\title{
Fabrication and Characterization of Thermoelectric Microgenerators with Carbon Nanotube
}

\author{
Chun-Chia Yeh, Ching-Liang Dai* and Hsi-Fu Shih \\ Department of Mechanical Engineering, National Chung Hsing University, \\ Taichung, 402 Taiwan, R.O.C.
}

(Received June 10, 2013; accepted September 26, 2013)

Key words: thermocouple, thermoelectric generator, CMOS, carbon nanotubes

In this paper, we present the fabrication and characterization of a thermoelectric microgenerator. The thermoelectric microgenerator is composed of 370 thermocouples in series, and each thermocouple is formed by p-type and n-type polysilicon strips. The output power of the microgenerator depends on the temperature difference between hot and cold parts of the thermocouples. To increase the output power of the microgenerator, the hot part of thermocouples is designed as a suspended structure, and multiwalled carbon nanotubes (MCNTs) are coated on the microgenerator. The thermoelectric microgenerator was fabricated using the standard $0.18 \mu \mathrm{m}$ complementary metal oxide semiconductor (CMOS) process and a postprocess. The postprocess uses reactive ion etching (RIE) to release the suspended hot part structure of the microgenerator. The finite element method software, ANSYS, is employed to simulate the temperature distribution of the microgenerator. The experimental results show that the microgenerator with MCNTs has an output voltage per area of $0.18 \mathrm{mV} \cdot \mathrm{mm}^{-2} \cdot \mathrm{K}^{-1}$.

\section{Introduction}

In 1823, Seebeck discovered that two different metal junctions produced a potential as the junctions had a temperature difference. This is the thermoelectric principle. Various thermoelectric generators were designed and developed according to this principle. ${ }^{(1,2)}$ The thermoelectric generator is a type of renewable energy conversion device that can convert waste and natural heat sources into electrical power. Several studies have applied thermoelectric generators in various instruments to supply electrical power. For instance, Knight and Collinsa ${ }^{(3)}$ proposed a device to capture thermoelectric energy where one side of the device was immersed in water and the other side was exposed to solar radiation, so that the device had a high-temperature source and a lowtemperature sink. Energy was extracted as heat flows from the hot side to the cold side. The thermoelectric generator was used for wireless computing and mobile devices.

*Corresponding author: e-mail: cldai@dragon.nchu.edu.tw 
Recently, micromachining technology has been employed to fabricate various thermoelectric generators. For instance, Jovanovic and Ghamaty ${ }^{(4)}$ presented a thermoelectric generator manufactured by a thin-film quantum well thermoelectric technique, and the device volume was largely reduced. The quantum wells were nanostructured multilayer films. Wang et al. ${ }^{(5)}$ utilized bulk material of $\mathrm{Bi}_{0.5} \mathrm{Sb}_{1.5} \mathrm{Te}_{3}$ to develop a thermoelectric generator for application in self-powered wireless sensor networks; the generator could produce a power of $2.7 \mathrm{~mW}$ under typical conditions. A thermoelectric generator, proposed by Wang et al., ${ }^{(6)}$ was made using the thermoelectric materials of n-type and p-type $\mathrm{Bi}_{2} \mathrm{Te}_{3}$ nanowires, and it could be applied in microelectronic devices. Yang et al. ${ }^{(7)}$ adopted the complementary metal oxide semiconductor (CMOS) process to produce a thermoelectric generator with a thermal isolation cavity and thermocouples with different aspect ratios. The output voltage factor of the generator was $27.88 \mathrm{mV} \cdot \mathrm{mm}^{-2} \cdot \mathrm{K}^{-1}$ and its output power factor was $47.3 \mathrm{nW} \cdot \mathrm{mm}^{-2} \cdot \mathrm{K}^{-2}$. Glatz et al. ${ }^{(8)}$ manufactured a thermoelectric generator on flexible substrate. The generator was fabricated by subsequent electrochemical deposition of $\mathrm{Cu}$ and $\mathrm{Ni}$ in a flexible polymer mold formed by photolithographic patterning of SU-8, and it had an output power of $12.0 \mathrm{nW} / \mathrm{cm}^{2}$ at a temperature difference of $0.12 \mathrm{~K}$.

The standard CMOS process has been utilized to fabricate various microdevices. ${ }^{(9-12)}$ Microdevices fabricated by this process have a potential for integration with IC as a

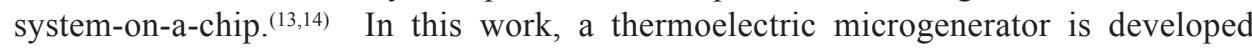
using the standard $0.18 \mu \mathrm{m}$ CMOS process. The microgenerator is composed of 370 thermocouples in series, and it needs a postprocess ${ }^{(15,16)}$ to release the suspended structure of the thermocouples. Ghosh et al. ${ }^{(17)}$ used thermal energy to eradicate a tumor, and the thermal energy was generated by multiwalled carbon nanotubes (MCNTs) that absorbed heat radiation. Thereby, the MCNTs are coated on the microgenerator to increase the heat absorption at the hot part of the thermocouples.

\section{Design of Generator}

Figure 1 shows the schematic structure of the thermoelectric microgenerator. The microgenerator consists of 370 thermocouples in series, and each thermocouple is

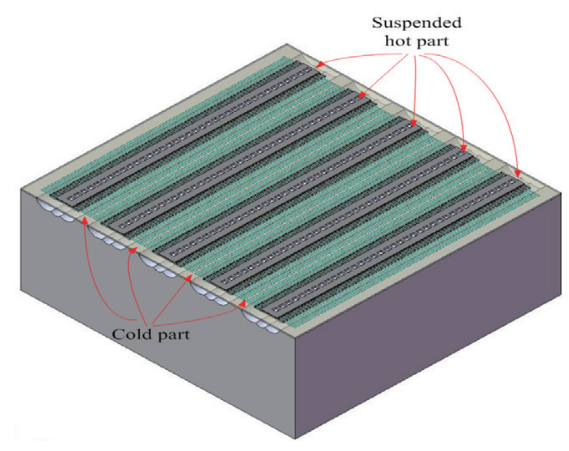

Fig. 1. (Color online) Schematic structure of thermoelectric microgenerator. 
constructed using p-type and n-type polysilicon strips. The output voltage of the thermoelectric microgenerator is given by ${ }^{(18)}$

$$
V_{\text {out }}=N\left(\alpha_{\text {n-poly }}-\alpha_{\text {p-poly }}\right)\left(T_{\mathrm{h}}-T_{\mathrm{c}}\right),
$$

where $N$ is the number of thermocouples, $\alpha_{\text {n-poly }}$ is the Seebeck coefficient of n-type polysilicon, $\alpha_{\mathrm{p} \text {-poly }}$ is the Seebeck coefficient of p-type polysilicon, $T_{\mathrm{h}}$ is the temperature of the hot part of the thermocouples, and $T_{\mathrm{c}}$ is the temperature of the cold part of the thermocouples. According to eq. (1), we know that the output voltage of the thermoelectric microgenerator is proportional to the temperature difference between the hot and cold parts of the thermocouples. To increase the temperature difference between the hot and cold parts of the thermocouples, the hot part of the thermocouples is designed as a suspended structure, and it is coated with MCNTs. The suspended hot part structure can isolate the heat sink, and the MCNTs can absorb the heat. The dimensions of each thermocouple are $100 \mu \mathrm{m}$ long, $8 \mu \mathrm{m}$ wide, and $0.275 \mu \mathrm{m}$ thick. The area of the microgenerator is $1.2 \times 1.24 \mathrm{~mm}^{2}$.

The finite element method software, ANSYS, is used to simulate the temperature distribution of the thermoelectric microgenerator. The model of the microgenerator is established in accordance with Fig. 1, followed by meshing the model. The materials of the microgenerator include polysilicon, MCNTs, silicon dioxide, aluminum, and silicon substrate. The thermal conductivities of the materials are as follows: ${ }^{(19)}$ aluminum, $237 \mathrm{~W} / \mathrm{m} \cdot \mathrm{K}$; silicon dioxide, $1.25 \mathrm{~W} / \mathrm{m} \cdot \mathrm{K}$; polysilicon, $31 \mathrm{~W} / \mathrm{m} \cdot \mathrm{K}$; MCNTs, $450 \mathrm{~W} / \mathrm{m} \cdot \mathrm{K}$; silicon substrate, $149 \mathrm{~W} / \mathrm{m} \cdot \mathrm{K}$. Figure 2 shows the simulation of the temperature distribution for the thermoelectric microgenerator. In this simulation, the heat source of $400 \mathrm{~K}$ was inputted into the generator. The results revealed that the temperature difference between the hot and cold parts of the thermocouples was $6.7 \mathrm{~K}$. Furthermore, the relationship between the heat source and the temperature difference of the microgenerator is evaluated. Figure 3 shows the variation of the temperature difference related to the heat source. The simulation results showed that the temperature difference of the microgenerator varied from 0.1 to $6.7 \mathrm{~K}$ as the temperature of the heat source increased from 300 to $400 \mathrm{~K}$.

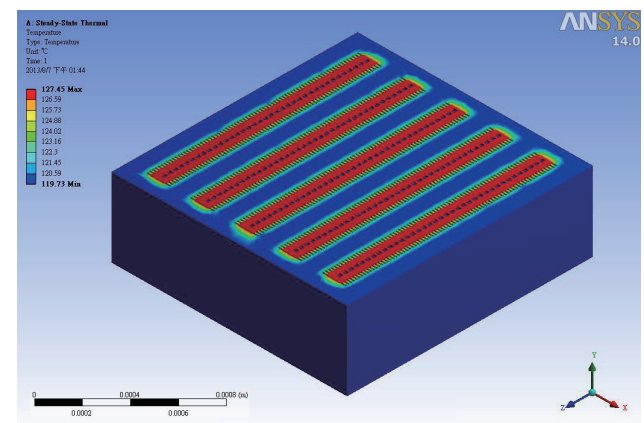

Fig. 2. (Color online) Temperature distribution of generator. 
Taking $n=370, \alpha_{\text {n-poly }}-\alpha_{\text {p-poly }}=0.789 \mu \mathrm{V} / \mathrm{K}$ and substituting the values into eq. (1), the output voltage of the microgenerator related to the temperature difference can be obtained. Figure 4 shows the relationship between the temperature difference and the output voltage of the microgenerator. The results showed that the output voltage of the microgenerator was $0.73 \mathrm{mV}$ at the temperature difference of $2.5 \mathrm{~K}$.

If the external load of the thermoelectric microgenerator is the same as its internal load, the maximum output power of the microgenerator is given by ${ }^{(18)}$

$$
P_{\max }=\frac{V_{\text {out }}^{2}}{4 R},
$$

where $P_{\max }$ is the maximum output power of the microgenerator, $V_{\text {out }}$ is the output voltage of the microgenerator, and $R$ is the resistance of the microgenerator. In this design, the number of thermocouples is 370; the Seeback coefficient difference $\alpha_{\mathrm{n} \text {-poly }}-\alpha_{\mathrm{p} \text {-poly }}$ is 0.789 $\mu \mathrm{V} / \mathrm{K}$, and the resistance $R$ is $12 \mathrm{k} \Omega$. Substituting the values into eq. (2), the maximum output power of the microgenerator can be obtained. Figure 5 shows the evaluation results of maximum output power for the microgenerator. The results revealed that the output power of the microgenerator was $11.1 \mathrm{pW}$ at the temperature difference of $2.5 \mathrm{~K}$.
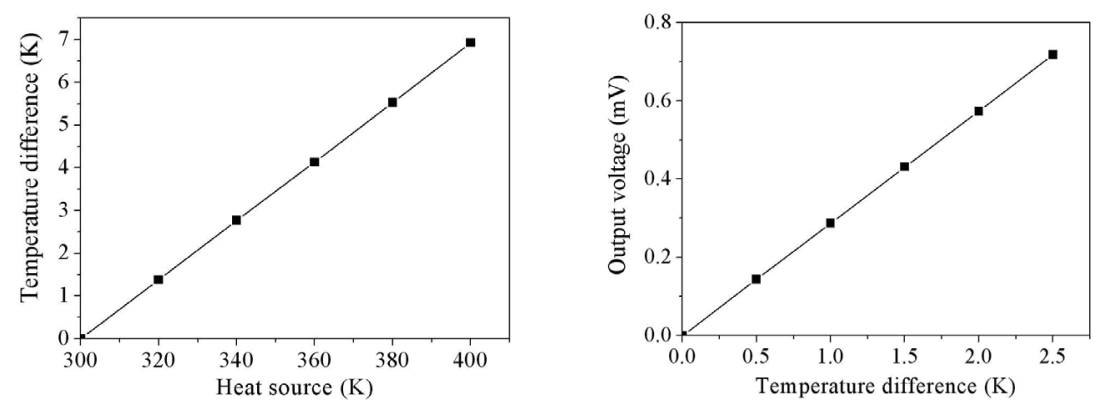

Fig. 3 (left). Relationship between temperature difference and heat source.

Fig. 4 (right). Evaluation of output voltage for microgenerator.

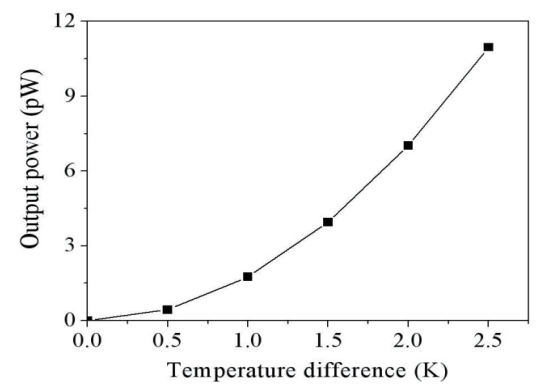

Fig. 5. Evaluation of output power for microgenerator. 


\section{Fabrication of Generator}

The thermoelectric microgenerator with MCNTs was fabricated using the standard 0.18 $\mu \mathrm{m}$ CMOS process of Taiwan Semiconductor Manufacturing Company (TSMC). Figure 6 illustrates the fabrication flow of the thermoelectric microgenerator. Figure 6(a) shows the cross-sectional view of the microgenerator after completion of the CMOS process. To obtain the suspended hot part of the microgenerator, a postprocess was employed to remove the silicon dioxide. ${ }^{(20)}$ Figure 6(b) shows the etched sacrificial silicon dioxide. A dry etching by reactive ion etching (RIE) with $\mathrm{CF}_{4} / \mathrm{O}_{2}$ was used to etch the sacrificial silicon dioxide ${ }^{(21)}$ and to expose the silicon substrate. As shown in Fig. 6(b), the hot part of the microgenerator stands on the silicon substrate. Figure 6(c) shows the silicon substrate removed. An isotropic dry etching by RIE with $\mathrm{SF}_{6} / \mathrm{O}_{2}$ was utilized to etch the silicon substrate ${ }^{(22,23)}$ and to obtain the suspended hot part of the microgenerator. Figure 7 shows an optical image of the thermoelectric microgenerator after the etching process. Figure 6(d) shows that the MCNTs are coated on the microgenerator. An MCNT water of $2 \mathrm{wt} \%$ was dropped on the microgenerator, followed by baking in an oven at $120{ }^{\circ} \mathrm{C}$. Figure 8 shows a scanning electron microscopy (SEM) image of the MCNTs. Figure 9 shows a side-view SEM image of the microgenerator. The silicon substrate under the hot part structure was removed, so the hot part structure was suspended. As shown in Fig. 9, the MNCTs are coated on the suspended hot part of the microgenerator.

\section{Results and Discussion}

The thermoelectric microgenerator was characterized using a heater, an infrared thermometer, an LCR meter and a multifunction electrical meter. The heater
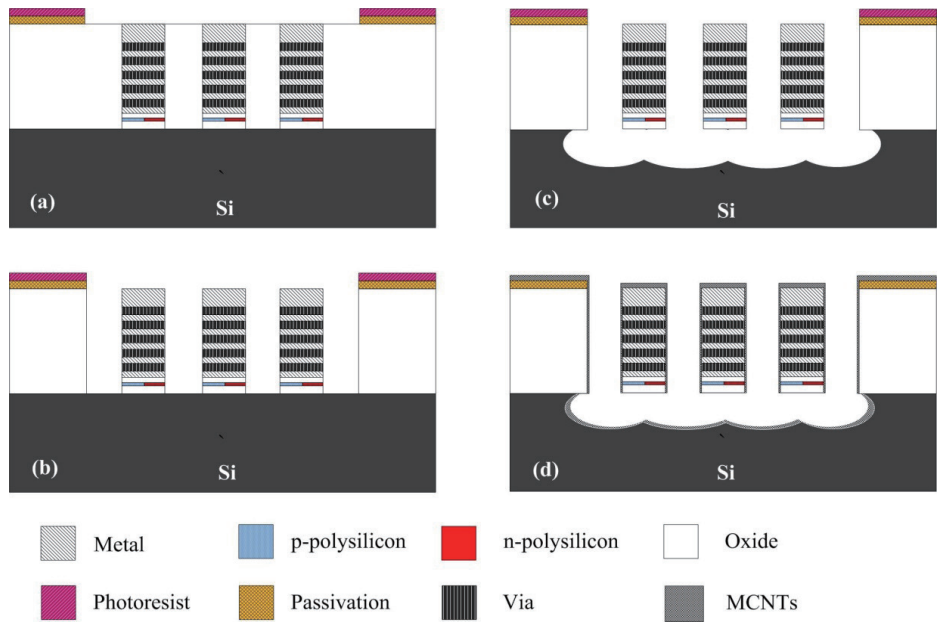

Fig. 6. (Color online) Process flow of microgenerator; (a) after the CMOS process, (b) etching of silicon oxide layer, (c) etching of silicon substrate, and (d) coating of the MCNTs film. 


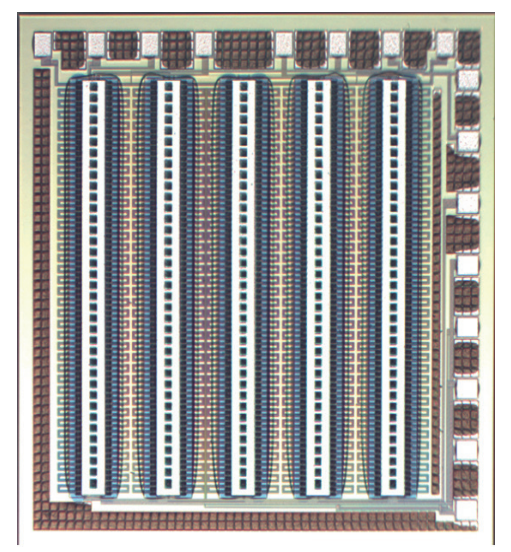

Fig. 7. (Color online) Optical image of microgenerator after etching.
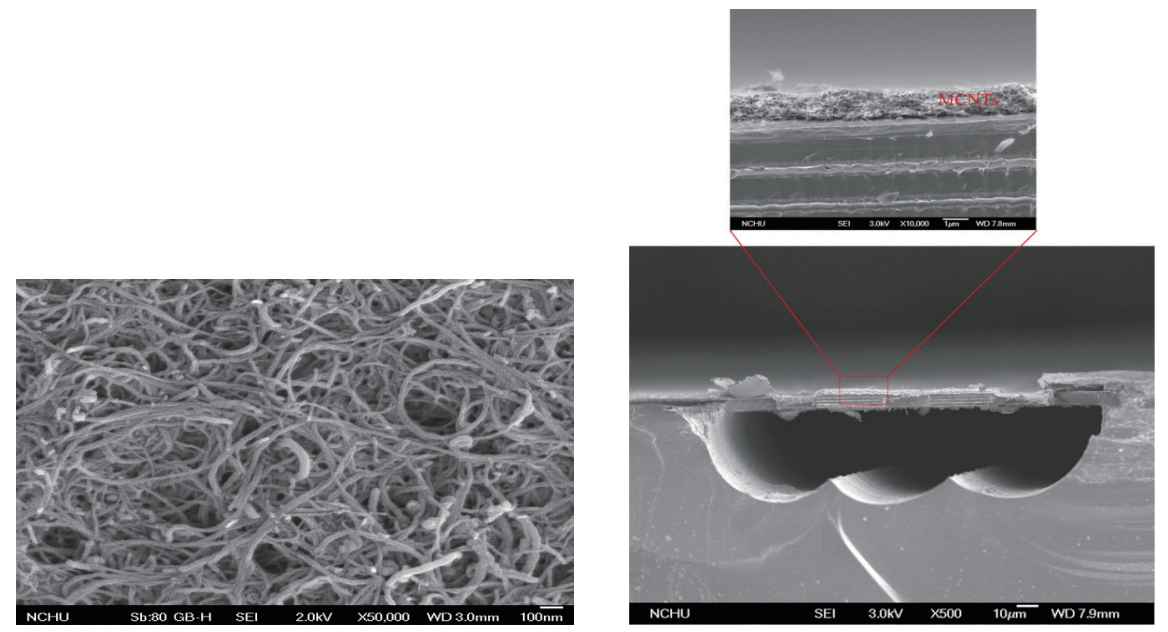

Fig. 8 (left). SEM image of MCNTs.

Fig. 9 (right). SEM cross-sectional image of microgenerator.

was utilized to provide the heat source to the microgenerator, and the infrared thermometer was employed to detect the temperature difference between the hot and cold parts of the thermocouples. The LCR meter was used to measure the resistance of the microgenerator, and the measured results showed that the resistance of the microgenerator was $11.5 \mathrm{k} \Omega$. The output voltage of the microgenerator was detected using the multifunction electrical meter.

To characterize the function of MCNTs for the microgenerator, the temperature difference between the hot and cold parts of the microgenerator with/without MCNTs, respectively, was measured. Figure 10 shows the temperature difference of the microgenerator with/without MCNTs. The results showed that the temperature difference 
of the microgenerator with MCNTs exceeded that of the microgenerator without MCNTs.

Figure 11 shows the measured results of the output voltage for the microgenerator with MCNTs. The results revealed that the microgenerator with MCNTs had an output voltage of $0.25 \mathrm{mV}$ at the temperature difference of $1 \mathrm{~K}$ and an output voltage of $0.7 \mathrm{mV}$ at the temperature difference of $2.5 \mathrm{~K}$. The output voltage per area of the microgenerator with MCNTs was $0.18 \mathrm{mV} \cdot \mathrm{mm}^{-2} \cdot \mathrm{K}^{-1}$. In comparison with the simulation results in Fig. 4 , the simulated output voltage of the microgenerator was $0.73 \mathrm{mV}$ at the temperature difference of $2.5 \mathrm{~K}$, so the percentage of error was about $4 \%$.

The output power of the microgenerator with MCNTs was evaluated using its output voltage. On the basis of the measured output voltage in Fig. 11 and the resistance $R=$ $11.5 \mathrm{k} \Omega$, the maximum output power of the microgenerator with MCNTs was obtained according to eq. (2). Figure 12 shows the maximum output power of the microgenerator with MCNTs. The results showed that the microgenerator with MCNTs had an output power of $1.9 \mathrm{pW}$ at the temperature difference of $1 \mathrm{~K}$ and an output power of $10.6 \mathrm{pW}$ at the temperature difference of $2.5 \mathrm{~K}$. The power factor of the microgenerator with MCNTs was $1.14 \mathrm{pW} \cdot \mathrm{mm}^{-2} \cdot \mathrm{K}^{-2}$.

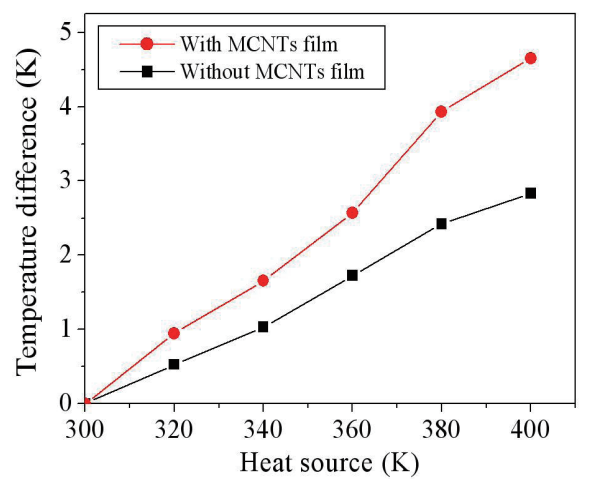

Fig. 10. (Color online) Temperature difference of thermocouples.
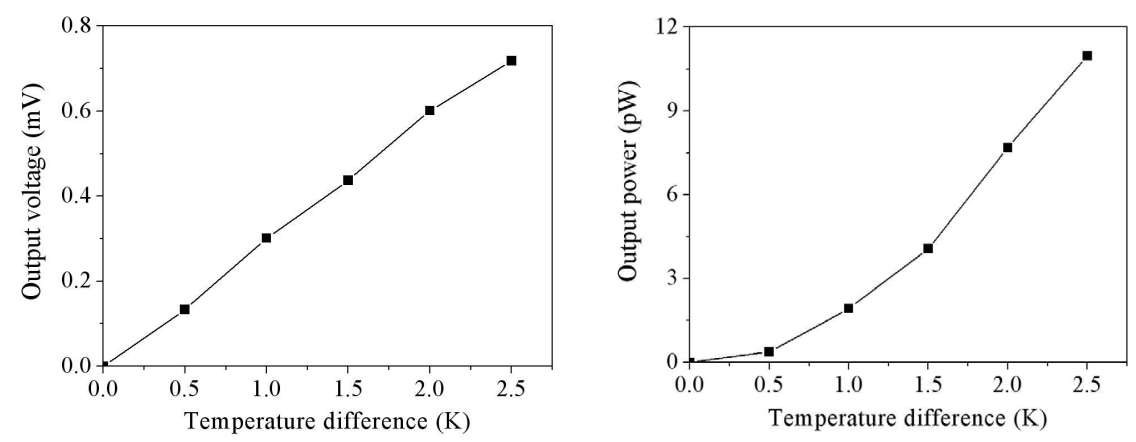

Fig. 11 (left). Measured results of output voltage for microgenerator.

Fig. 12 (right). Measured results of output power for microgenerator. 


\section{Conclusion}

A thermoelectric microgenerator has been fabricated using the CMOS process and a postprocess. The postprocess used RIE with $\mathrm{CF}_{4} / \mathrm{O}_{2}$ to etch the sacrificial silicon dioxide layer for exposing the silicon substrate, followed by employing RIE with $\mathrm{SF}_{6} / \mathrm{O}_{2}$ to etch the silicon substrate for releasing the hot part of the microgenerator. Then, the MCNTs were coated on the hot part structure of the microgenerator. In thermoelectric theorem, the output voltage of the thermoelectric generator is proportional to the temperature difference between its hot and cold parts. In this work, the MCNTs were utilized to increase heat absorption at the hot part of the microgenerator for enhancing the temperature difference. The experimental results showed that the temperature difference of the microgenerator with MCNTs exceeded that of the microgenerator without MCNTs. In addition, experiments showed that the output voltage of the microgenerator with MCNTs was $0.7 \mathrm{mV}$ at the temperature difference of $2.5 \mathrm{~K}$, and its output voltage per area was $0.18 \mathrm{mV} \cdot \mathrm{mm}^{-2} \cdot \mathrm{K}^{-1}$. The output power of the microgenerator with MCNTs was $10.6 \mathrm{pW}$ at the temperature difference of $2.5 \mathrm{~K}$, and its power factor was 1.14 $\mathrm{pW} \cdot \mathrm{mm}^{-2} \cdot \mathrm{K}^{-2}$.

\section{Acknowledgements}

The authors would like to thank the National Center for High-Performance Computing (NCHC) for chip simulation, National Chip Implementation Center (CIC) for chip fabrication, National Nano Device Laboratories (NDL) for chip post-processing, and the National Science Council of the Republic of China for financially supporting this research under Contract No. NSC 101-2221-E-005-006-MY3.

\section{References}

1 K. Yazawa and A. Shakouri: Environ. Sci. Technol. 45 (2011) 7548.

2 P. H. Kao, P. J. Shih, C. L. Dai and M. C. Liu: Sensors 10 (2010) 1315.

3 C. Knight and M. Collinsa: Proc. SPIE 7288 (2009) 72880Y.

4 V. Jovanovic and S. Ghamaty: Proc. SPIE 6173 (2006) 61730G.

5 W. S. Wang, W. Magnin, N. Wang, M. Hayes, B. O'Flynn and C. O'Mathuna: J. Phys. Conf. Ser. 307 (2011) 012030.

6 W. Wang, F. Jia, Q. Huang and J. Zhang: Microelectron. Eng. 77 (2005) 223.

7 S. M. Yang, T. Lee and C. A. Jeng: Sens. Actuators A 153 (2009) 244.

8 W. Glatz, S. Muntwyler and C. Hierold: Sens. Actuators, A 132 (2006) 337.

9 C. L. Dai and J. H. Chen: Microsyst. Technol. 12 (2006) 1143.

10 C. L. Dai, H. J. Peng, M. C. Liu, C. C. Wu, H. M. Hsu and L. J. Yang: Jpn. J. Appl. Phys. 44 (2005) 6804.

11 Y. C. Cheng, C. L. Dai, C. L. Lee, P. H. Chen and P. Z. Chang: Microsyst. Technol. 11 (2005) 444.

12 C. L. Dai, H. M. Hsu, C. M. Tsai, M. M. Hsieh and M. W. Chang: Microelectron. J. 38 (2007) 519.

13 M. Z. Yang, C. L. Dai and D. H. Lu: Sensors 10 (2010) 10095.

14 C. L. Dai, Y. W. Tai and P. H. Kao: Sensors 7 (2007) 3386. 
15 C. L. Dai: Microelectron. Eng. 83 (2006) 2543.

16 C. L. Dai and Y. L. Chen: Sensors 7 (2007) 2660.

17 S. Ghosh, S. Dutta, E. Gomes and D. Carroll: ACS Nano 3 (2009) 2667.

18 N. Sato, K. Kuwabara, K. Ono, T. Sakata, H. Morimura, J. Terada, K. Kudou, T. Kamei, M. Yano, K. Machida and H. Ishii: Jpn. J. Appl. Phys. 46 (2007) 6062.

19 J. Xie, C. Lee and H. Feng: J. Microelectromech. Syst. 19 (2010) 317.

20 P. H. Kao, C. L. Dai, C. C. Hsu and C. Y. Lee: Sensors 9 (2009) 2062.

21 C. L. Dai, H. L. Chen and P. Z. Chang: J. Micromech. Microeng. 11 (2001) 612.

22 C. L. Dai, F. Y. Xiao, Y. Z. Juang and C. F. Chiu: J. Micromech. Microeng. 15 (2005) 98.

23 C. L. Dai, K. S. Yen and P. Z. Chang: J. Micromech. Microeng. 11 (2001) 697. 